$03,05,08,13$

\title{
Аномальный магнетизм поверхности нанокристаллических оксидов $\mathrm{TiO}_{2}$
}

\author{
() А.Е. Ермаков, М.А. Уймин, А.В. Королев, А.С. Волегов, И.В. Бызов, \\ Н.Н. Щеголева, А.С. Минин
}

Институт фризики металлов им. М.Н. Михеева УрО РАН,

Екатеринбург, Россия

E-mail: yermakov@imp.uran.ru

(Поступила в Редакцию 8 августа 2016 г.)

Выполнены исследования магнитных свойств кислород-дефицитного нанокристаллического недопированного диоксида титана, синтезированного газофазным, электровзрывным и химическим методами. Дефектное состояние контролировалось с помощью восстановительных обработок в вакууме или в среде водорода. Показано, что дефектное состояние поверхности нанокристаллических оксидов (например, наличие вакансий по анионной подрешетке и других дефектов) оказывает доминирующее влияние на формирование магнитных свойств исследуемых образцов. Основные вклады в магнетизм наночастиц $\mathrm{TiO}_{2}$ после восстановительных обработок - это парамагнитный вклад матрицы, парамагнитный вклад Кюри-Вейсса и вклад спонтанного магнитного момента, обусловленного существованием областей с различным спиновым порядком. Установлено существование гетерогенного магнитного состояния в нанопорошках $\mathrm{TiO}_{2}$; так при низкой температуре обнаружены смещенные петли гистерезиса, как результат возможного набора магнитных состояний с различным спиновым порядком. Показано, что мягкое компактирование или растирание нанопорошков в агатовой ступке, при котором увеличивается только доля контактирующих поверхностей нанопорошков, приводит к существенному росту намагниченности, иногда более чем в 2 раза, независимо от метода синтеза нанопорошков и исходного фазового состояния $\mathrm{TiO}_{2}$ (структура анатаза или рутила). Этот экспериментальный факт доказывает ключевую роль поверхностных дефектов и носителей магнитного момента с различными спиновыми конфигурациями, локализованных в основном на поверхности наночастиц. Изменение намагниченности при компактировании наблюдается только в том случае, когда исходное магнитное состояние имеет нелинейный „квазисуперпарамагнитный“ характер кривой намагничивания. В результате, преимущественно, обменного взаимодействия между наночастицами с фрустрированным характером спинового упорядочения на поверхности наночастиц усиливается ферромагнитный вклад при их контакте.

Выражаем благодарность Российскому научному фонду за финансовую поддержку исследований (грант № 16-12-10004).

Электронно-микроскопические исследования проводились в ЦКП ОЭМ ИФМ УрО РАН.

DOI: $10.21883 /$ FTT.2017.03.44154.324

\section{1. Введение}

Обнаружение спонтанной намагниченности в полупроводниках на основе $\mathrm{TiO}_{2}$ и $\mathrm{Cu}_{2} \mathrm{O}, \mathrm{CuO}, \mathrm{Al}_{2} \mathrm{O}_{3}$, $\mathrm{CeO}_{2}, \mathrm{HfO}_{2}$ [1-8] и других оксидов, не содержащих в своем составе магнитных допантов, представляет не только научный интерес, в связи с необычной природой магнетизма, но и открывает возможности применения в катализе, спинтронике и бионанотехнологиях [9]. Одно из наиболее часто встречаемых в литературе объяснений причин возникновения магнетизма в недопированном $\mathrm{TiO}_{2}$ (появление спонтанного магнитного момента) с высокой температурой Кюри состоит в том, что природа магнитного упорядочения в этих соединениях может быть обусловлена существованием дефектов - вакансий по кислородной подрешетке или межузельными атомами титана и наличием катионов с измененным валентным состоянием [10-13].

Однако, даже в этих перечисленных случаях трудно объяснить появление магнитного упорядочения при ма- лых концентрациях (проценты и доли процентов) магнитных ионов, не принимая во внимание пространственную локализацию носителей магнитного момента, так как прямое обменное взаимодействие не достигается, а механизм RKKY (Рудерман-Киттель-Касуя-Иосида) не является оперативным из-за непроводящей матрицы. Следует подчеркнуть фундаментальный факт, состоящий в том, что дефекты (например, вакансии и примесные атомы), из-за более низкой энергии образования на поверхности, по сравнению с объемом, преимущественно локализованы в поверхностных слоях [14] и, следовательно, концентрация примесей и вакансий увеличивается вблизи поверхности образца по сравнению с объемом $[15,16]$. Действительно, анализ литературных данных и экспериментальных результатов с использованием прямых методов (3DAP - 3D Atom probe и позитронная аннигиляция) убедительно демонстрирует, что поверхность наночастиц (или границ зерен) является энергетически предпочтительным местом локализации дефектов и примесей и, следовательно, основным источ- 
ником магнитных неоднородностей [17-22]. На основе анализа природы и источников магнетизма в диоксиде титана можно утверждать, что ключевым фактором для объяснения и понимания механизма появления магнетизма является существование дефектов различного типа, однако для наносостояния принципиальной и фундаментальной особенностью оказывается пространственная локализация дефектов, как следствие существенного вклада поверхности. Таким образом, анализ литературных данных, на наш взгляд, убедительно и обоснованно в ряде случаев указывает на доминирующий вклад поверхностных состояний в физико-химические свойства нанообъектов, однако в подавляющем большинстве работ по магнетизму оксидных наноматериалов вклад поверхностных состояний обсуждается мало или просто не принимается во внимание.

Впервые в работах [23-25] было обращено особое внимание на сложный характер магнитного упорядочения на поверхности магнитоупорядоченных наночастиц (гамма- $\mathrm{Fe}_{2} \mathrm{O}_{3}, \mathrm{NiO}, \mathrm{NiFe}_{2} \mathrm{O}_{4}$ ), которое, по мнению авторов, следует описывать как фрустрированное неупорядоченное состояние спинов, обусловленное конкуренцией обменных взаимодействий разного знака с учетом локальной анизотропии.

Если допустить, что поверхностное магнитное состояние нанокристаллических оксидов может существенно отличаться как типом магнитного порядка в системе магнитных носителей, так и характером обменного взаимодействия между ними, можно предположить, что взаимодействие наночастиц между собой может быть очень критичным и чувствительным для реализации различных спиновых структур и магнитного упорядочения [2629]. Контактное взаимодействие нескольких межатомных слоев поверхности наночастиц с нарушенной пространственной симметрией, напряжениями, с дефектами по анионной и катионной подрешетке, содержащих магнитные области (парамагнитной природы или имеющих неколлинеарную магнитную структуру), может оказать заметное влияние на магнитное состояние (упорядочение спинов) периферийных слоев наночастиц и всей системы в целом.

Основной задачей настоящей работы является исследование структурного состояния и магнитных свойств в нанокристаллических диоксидах титана, синтезированных газофазным и электровзрывным методом. Также для анализа и сопоставления магнитных свойств нами были исследованы образцы диоксида титана на основе ST-21 (Ishihara Co.). В работе предполагается провести исследование структурного состояния и магнитных свойств нестехиометрического недопированного $\mathrm{TiO}_{2}$ при различных режимах термообработки (восстановительный отжиг в вакууме и водороде) в нестехиометрическом $\mathrm{TiO}_{2}$ и выяснить роль поверхностных дефектов независимо от фазового состояния $\mathrm{TiO}_{2}$ (рутил или анатаз). При этом основное внимание будет уделено не только изучению природы формирования магнитного момента в этих оксидах с различными фазами (рутил, анатаз), а исследованию особенностей изменения спонтанного магнитного момента в периферийных областях наночастиц, а также их поведению при контактном взаимодействии как для рутильной, так и анатазной фазы. Особое внимание будет уделено обнаружению и изучению сдвига петель гистерезиса в нанокристаллическом $\mathrm{TiO}_{2}$, характерного для гетерогенных систем с различными спиновыми конфигурациями (АФ, ФЕ, скошенные структуры, спиновые стекла и т.п.).

\section{2. Приготовление и аттестация образцов}

Нанокристаллические материалы на основе $\mathrm{TiO}_{2}$ были синтезированы газофазным (ГФ) - gas-condensation (GC) - и электровзрывным (ЭВ) - explosive wire $(\mathrm{EW})$ методами [30,31]. В работе также исследовались нанопорошки ST-21 (Ishihara Co.) в форме анатаза со средним размером части $20 \mathrm{~nm}$. В результате $\mathrm{GC}$ синтеза формировались порошки диоксида титана, которые собирались на тканевом фильтре. Средний размер наночастиц $\mathrm{TiO}_{2}$ составлял около $20 \mathrm{~nm}$. Метод синтеза диоксида титана электровзрывным методом подробно описан в работе [32]. Порошок имеет большую неоднородность частиц по размеру: средний размер наночастиц после EW синтеза составлял около 30-40 nm, а дисперсия 10-100 nm. В процессе испарения металла при GC и EW синтезе в среде, содержащей кислород, происходило окисление металла на этапе образования наночастиц и, таким образом, можно было получать оксиды металлов с частично контролируемым фазовым составом и содержанием кислорода. Ранее нами было установлено [33], что даже при концентрациях кислорода в аргоне, заведомо превышающих необходимое количество для получения стехиометрического состава, как при EW, так и при GC синтезе, мы всегда получали существенный дефицит решеточного кислорода по анионной подрешетке. Отклонение от стехиометрии в $\mathrm{TiO}_{2-x}$ достигало достаточно большой величины до $x=0.2$ или $\mathrm{TiO}_{1.80-1.87}$ для нанопорошков сразу после газофазного синтеза, которые имели преимущественно структуру анатаза. Эти данные были получены методом ядерных реакций и обратного резерфордовского рассеяния с использованием изотопа ${ }^{18} \mathrm{O}$ в процессе синтеза, что позволило определить концентрацию решеточного кислорода [33]. Вероятно, при данных условиях синтеза большую роль играют термодинамические причины отклонения от стехиометрии, а именно в частицах формируется неравновесное состояние, содержащее высокую концентрацию точечных дефектов вблизи поверхности, существование которых, как это отмечается в некоторых работах, стабилизируется малым размером наночастицы [34]. Длительная выдержка образцов на воздухе заметно увеличивала концентрацию кислорода вплоть до стехиометрической 
и даже выше, например в результате сорбции кислорода и гидроксильных групп на поверхности наночастиц.

Нестехиометрический состав в наносостоянии также изменялся при отжиге в восстановительных средах - в вакууме или в среде водорода (давление $\mathrm{H}_{2}, 1$ или 5 bar). В массивном состоянии отжиг в вакууме не должен приводить к заметному восстановлению оксида $\mathrm{TiO}_{2}$, но, принимая во внимание малый размер наночастиц (средний $20 \mathrm{~nm})$, в котором энергия химических связей Ti-O, особенно на поверхности, может быть заметно меньше, чем в массивном состоянии, указанный восстановительный отжиг может быть достаточно эффективным. Отжиг в водороде при повышенных давлениях и относительно низких температурах также существенно изменяет физико-химические свойства диоксида титана в анатазной форме, в частности возрастает каталитическая активность после этой обработки. Однако следует отметить, что магнитные свойства порошка $\mathrm{TiO}_{2}$ после водородной обработки очень мало исследуются.

Загрязнения порошков ферромагнитными примесями в процессе синтеза не происходило, а чистота конечных продуктов определялась только чистотой исходных компонентов. Так, химическая чистота EW нанопорошков, определенная методом индуктивно-связанной плазмы, по разным примесям переходных металлов составляла по железу 0.077 , по кобальту 0.022, по никелю 0.028 wt.\%. Предельная величина намагниченности, в предположении образования чистых $3 d$-металлов, при такой концентрации может составлять величину около $0.2 \mathrm{emu} / \mathrm{g}$. Однако, если в наночастицах формируются оксиды на основе магнитных оксидов железа, что наиболее вероятно, этот вклад становится примерно более, чем в 2 раза меньше или около $0.1 \mathrm{emu} / \mathrm{g}$. Как мы увидим далее по тексту, максимальная намагниченность при температуре кипения жидкого гелия в полях до 5 Т для образцов $\mathrm{EW}$ и $\mathrm{GC}$ варьируется в пределах от 0.25 до $0.4 \mathrm{emu} / \mathrm{g}$, что существенно больше, чем ожидаемая величина с учетом содержания сильно магнитных оксидов на основе железа. Порошок ST-21 (Ishihara Co.) использовался как эталонный, в котором концентрация железа не превышала 0.01 wt.\%. Предельная величина намагниченности с учетом чистых примесей (например, Fe) в этом случае не должна превышать $0.02 \mathrm{emu} / \mathrm{g}$.

Средний размер частиц был оценен с помощью анализа данных просвечивающей электронной микроскопии (микроскоп Philips CM30) и рентгеноструктурных данных по ширине линий методом Дебая-Шерера (размер блоков ОКР). Рентгеноструктурные дифракционные исследования проводились на дифрактометре ДРОН-6 в излучении $K_{\alpha}$ хрома $(\lambda=2.29 \AA)$.

Изотермы $M(H) T=$ const $(M-$ намагниченность, $H$ - напряженность магнитного поля) и политермы $M(T) H=$ const были получены на СКВИД-магнитометре MPMS-5XL (Quantum Design) в полях до $5 \mathrm{~T}$. Измерения намагниченности при комнатной температуре осуществлялись также на весах Фарадея в полях до $12 \mathrm{kOe}$.
Для качественного анализа нестехиометрии и контроля поверхностных состояний в недопированном $\mathrm{TiO}_{2}$ использовался метод циклической вольтамперометрии (ЦВА). Для регистрации вольтамперных зависимостей использовался потенциостат P30-IM (OOO „Elins“, Черноголовка). ЦВА и импедансная спектроскопия при определенном наборе условий представляет собой эффективный метод для определения плотности электронных состояний в металл-оксидных наноструктурированных полупроводниках [35,36]. Установлено [37,38], что реакционная способность, фотокаталитическая активность, связанная с переносом заряда, например на основе $\mathrm{TiO}_{2}$, определяется дефектным состоянием и химическим потенциалом электронов.

Компактирование образцов проводилось двумя методами, путем растирания порошка $\mathrm{TiO}_{2}$ в агатовой ступке или компактированием в матрице, изготовленной из титана. Давление при компактировании в пресс-форме из титана составляло $550 \mathrm{MPa}$.

В таблице представлены параметры и характеристики исследуемых образцов, синтезированных разными методами (GC и $\mathrm{EW})$ в исходном состоянии сразу после синтеза и последующих термообработок.

\section{3. Результаты эксперимента и их обсуждение}

3.1. Анализ потенциодинамических кри вых для нанокристаллического диоксида титана. На рис. 1 приведены потенциодинамические кривые для образца $\mathrm{TiO}_{2}-\mathrm{GC}$, оксида титана, синтезированного ГФ методом, подвергнутого различным обработкам. Наиболее выраженный максимум (кривая 3) в области потенциалов $-800 \div-1000 \mathrm{mV}$ соответствует обработке образца в вакууме при $700^{\circ} \mathrm{C}, 0.5 \mathrm{~h}$, что может быть объяснено увеличением концентрации трех-

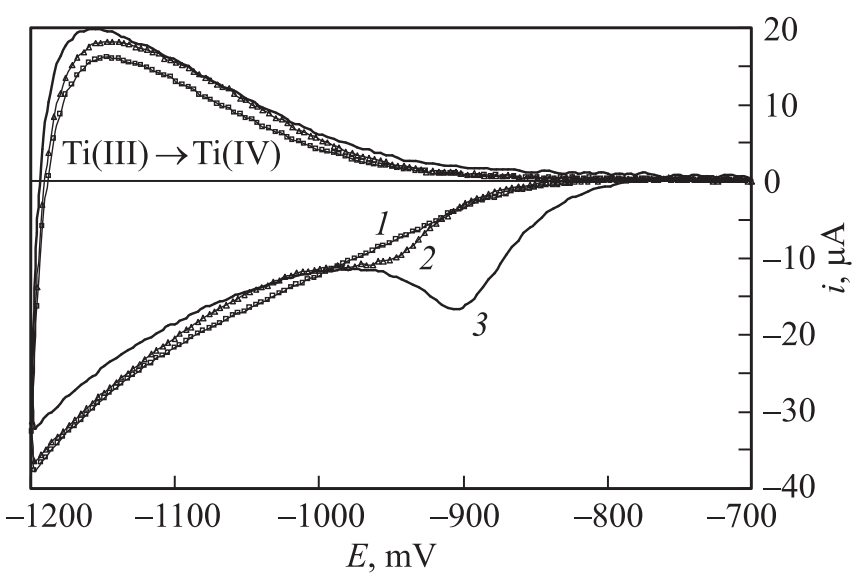

Рис. 1. Потенциодинамические кривые наночастиц оксида титана $\left(\mathrm{TiO}_{2}-\mathrm{GC}\right): 1-$ исходного, 2 и 3 - подвергнутых термообработке при $700^{\circ} \mathrm{C}$ на воздухе и в вакууме соответственно. 
Параметры образцов (средний размер, фазовый состав, удельная намагниченность при комнатной температуре) и режимы термообработок

\begin{tabular}{|c|c|c|c|c|}
\hline Образцы & Метод синтеза и теромообработка & $\begin{array}{c}\text { Средний } \\
\text { размер, нм }\end{array}$ & $\begin{array}{l}\text { Фазовый } \\
\text { состав }\end{array}$ & $\begin{array}{c}\text { Удельная намагниченность } \\
\text { при комнатной температуре }\end{array}$ \\
\hline $\mathrm{TiO}_{2}-\mathrm{GC}$ & $\begin{array}{l}\text { Газофазный синтез, } \\
\text { исходное состояние }\end{array}$ & 20 & $\begin{array}{l}50 \mathrm{wt} . \%(R) \\
+50 \mathrm{wt} . \%(A)\end{array}$ & $0.02 \mathrm{emu} / \mathrm{g}$, измеренная при $3 \mathrm{~T}$ \\
\hline $\mathrm{TiO}_{2}-\mathrm{GC}(1)$ & $\begin{array}{l}\text { Обработка ГФ образца } \\
\text { при } 900^{\circ} \mathrm{C} \text { в вакууме, } 0.5 \mathrm{~h}\end{array}$ & 60 & 100wt.\%(R) & $\begin{array}{l}0.044 \mathrm{emu} / \mathrm{g} \text {, измеренная при } 12 \mathrm{kOe} \\
\text { и } 0.067 \mathrm{emu} / \mathrm{g} \text {, измеренная при } 5 \mathrm{~T}\end{array}$ \\
\hline $\mathrm{TiO}_{2}$-EW & $\begin{array}{l}\text { Электровзрывной синтез, } \\
\text { исходное состояние после синтеза }\end{array}$ & $30-50$ & $\begin{array}{l}73 \text { wt. } \%(A) \\
+27 \text { wt. } \%(R)\end{array}$ & $0.004 \mathrm{emu} / \mathrm{g}$, измеренная при $12 \mathrm{kOe}$ \\
\hline $\mathrm{TiO}_{2}-\mathrm{EW}(1)$ & $\begin{array}{l}\text { Одноступенчатая обработка. } \\
\text { Обработка при } 900^{\circ} \mathrm{C} \text { в вакууме, } 0.5 \mathrm{~h}\end{array}$ & $\sim 100$ & 100 wt. $\%(\mathrm{R})$ & $0.06 \mathrm{emu} / \mathrm{g}$ \\
\hline $\mathrm{TiO}_{2}-\mathrm{EW}(2)$ & $\begin{array}{l}\text { Двухступенчатая обработка. } \\
\text { Обработка при } 550^{\circ} \mathrm{C}, 0.5 \mathrm{~h} \text { с последующей } \\
\text { обработкой в водороде (давление } 1 \text { bar) } \\
\text { при } 900^{\circ} \mathrm{C} \text { в течение } 0.5 \mathrm{~h}\end{array}$ & $\sim 100$ & 100 wt. $\%(\mathrm{R})$ & $0.03 \mathrm{emu} / \mathrm{g}$, измеренная при $12 \mathrm{kOe}$ \\
\hline $\begin{array}{l}\mathrm{TiO}_{2}-\mathrm{EW}(2)- \\
\text { компактирование }\end{array}$ & $\begin{array}{l}\text { Двухступенчатая обработка. } \\
\text { Обработка при } 550^{\circ} \mathrm{C}, 0.5 \mathrm{~h} \\
\text { с последующей обработкой в водороде } \\
\text { (давление } 1 \text { bar) при } 900^{\circ} \mathrm{C} \text { в течение } 0.5 \mathrm{~h} \text {, } \\
\text { затем компактирование в пресс-форме } \\
(550 \mathrm{MPa}) .\end{array}$ & $\sim 100$ & 100 wt. $\%(\mathrm{R})$ & $0.06 \mathrm{emu} / \mathrm{g}$, измеренная при $12 \mathrm{kOe}$ \\
\hline $\begin{array}{l}\text { ST-21 } \\
\text { (Ishihara Co.) }\end{array}$ & Химический метод, исходное состояние & 20 & 100 wt. $\%(\mathrm{~A})$ & $0.0008 \mathrm{emu} / \mathrm{g}$, измеренная при $12 \mathrm{kOe}$ \\
\hline ST-21- $\mathrm{H}_{2}$ & $\begin{array}{l}\text { Обработка при температуре } \\
700^{\circ} \mathrm{C}, 2 \mathrm{~h} \text { в водороде } \\
\text { при давлении } 5 \mathrm{bar}, \mathrm{c} \text { последующей } \\
\text { бработкой в вакууме при } 700^{\circ} \mathrm{C}, 4 \mathrm{~h}\end{array}$ & 30 & 100 wt. $\%(\mathrm{~A})$ & $\begin{array}{l}0.03 \mathrm{emu} / \mathrm{g} \text { после выдержки } \\
\text { на воздухе } 15 \text { дней стало } 0.02 \mathrm{emu} / \mathrm{g}\end{array}$ \\
\hline $\begin{array}{l}\mathrm{ST}-21-\mathrm{H}_{2}- \\
\text { растирание }\end{array}$ & $\begin{array}{l}\text { Обработка при температуре } 700^{\circ} \mathrm{C}, \\
2 \text { h в водороде при давлении } 5 \mathrm{bar}, \\
\text { с последующей обработкой в вакууме } \\
\text { при } 700^{\circ} \mathrm{C}, 4 \mathrm{~h}, \text { а затем растирание } \\
\text { в агатовой ступке }\end{array}$ & 30 & 100 wt. $\%(\mathrm{~A})$ & $\begin{array}{l}\text { После измельчения увеличилась } \\
\text { с } 0.02 \mathrm{emu} / \mathrm{g} \text { до } 0.04 \mathrm{emu} / \mathrm{g}\end{array}$ \\
\hline
\end{tabular}

валентных ионов титана. Наличие этого максимума связывают с локализованными поверхностными состояниями $[39,40]$.

Потенциодинамические кривые образцов, синтезированные в условиях дефицита кислорода, отличаются тем, что выраженный максимум в области $-800 \div-1000 \mathrm{mV}$ не формируется, однако начало процесса смещено на $50-100 \mathrm{mV}$ в анодную область и токи значительно больше, что можно предположительно объяснить высокой концентрацией ионов трехвалентного титана $\left(\mathrm{Ti}^{3+}\right)$. После термообработки на воздухе потенциодинамические кривые типичны для стехиометрических по кислороду образцов $\mathrm{TiO}_{2}$. Вакуумная термообработка дополнительно приводит к увеличению общей концентрации дефектов. Синтез в условиях дефицита кислорода приводит к формированию сильно дефектных структур, при термообработке на воздухе эти дефекты устраняются, что и регистрируется по усилению или ослаблению максимума в области $-800 \div-1000 \mathrm{mV}$.
Таким образом, можно сделать заключение, что термообработка при температурах около $700^{\circ} \mathrm{C}$ в вакууме приводит к локализации дефектов и состояний $\mathrm{Ti}^{3+}$ на поверхности наночастиц $\mathrm{TiO}_{2}$, без значительного спекания. При температурах термообработки выше $700^{\circ} \mathrm{C}$ происходит спекание образца (изменяется его дисперсность) и выявить закономерности изменения валентного состояния $\mathrm{Ti}^{3+}$ по данным вольтамперометрии не удается из-за снижения удельной поверхности.

3.2. Рентгеноструктурный анализ нанопорошков диоксида титана. Рентгеноструктурный анализ диоксидов титана в наносостоянии сразу после газофазного синтеза при различных концентрациях кислорода в аргоне регистрирует различные фазовые состояния $\mathrm{TiO}_{2}$. В подавляющем большинстве случаев это всегда сосуществование нескольких фаз, с преимущественной концентрацией одной из них. Даже при высоких концентрациях кислорода в буферном газе $\mathrm{Ar}$ при газофазном синтезе в нанокристаллическом образце 


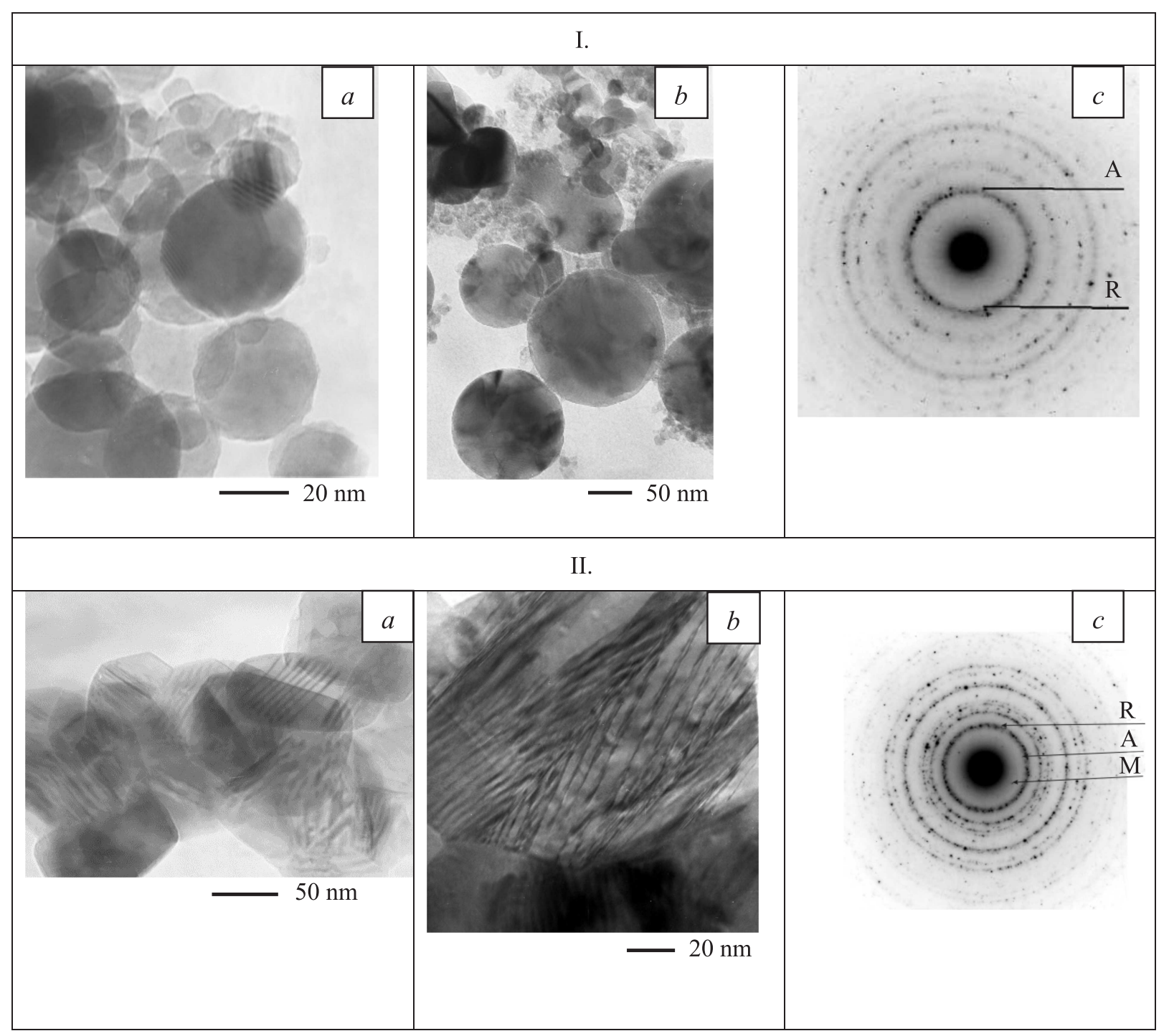

Рис. 2. Электронно-микроскопический анализ образцов (GC) и (EW) $\mathrm{TiO}_{2}$ после различных обработок (I, II, III, IV). (I). Электронно-микроскопические снимки образцов газофазного $\left(\mathrm{TiO}_{2}-\mathrm{GC}\right)(a)$ и электровзрывного $\left(\mathrm{TiO}_{2}\right.$-EW) $(b)$ и электронограмма $\left(\mathrm{TiO}_{2}-\mathrm{GC}\right)(c)$ в исходном состоянии сразу после синтеза. Смесь фаз рутила (R) и анатаза (A). (II). Электронномикроскопические снимки образца $\mathrm{TiO}_{2}-\mathrm{GC}$ после отжига при $800^{\circ} \mathrm{C}$ в вакууме, $30 \mathrm{~min}$. Соседние участки одного и того же

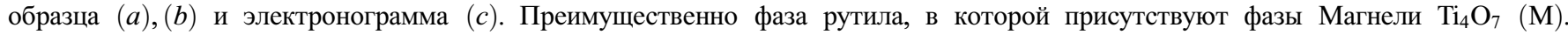
(III). Электронно-микроскопические снимки образца $\mathrm{TiO}_{2}-\mathrm{GC}$ после отжига в вакууме при $900^{\circ} \mathrm{C}, 30 \mathrm{~min}\left(\mathrm{TiO}_{2}-\mathrm{GC}(1)\right)$. Сoceдние участки одного и того же образца $(a)$, с фазой Магнели $\mathrm{Ti}_{4} \mathrm{O}_{7}(b)$ и электронограмма (c). (IV). Просвечивающая электронная микроскопия компактированных образцов $\mathrm{TiO}_{2}-\mathrm{GC}(1)$ после отжига в вакууме при $900^{\circ} \mathrm{C}, 0.5 \mathrm{~h}$. Соседние участки того же самого образца $(a),(b)$ и электронограмма $(c)$ с фазой Магнели $\mathrm{Ti}_{4} \mathrm{O}_{7}$.

всегда существует смесь двух фаз - рутила и анатаза. Фазовый состав образца $\mathrm{TiO}_{2}-\mathrm{GC}$ - это анатаз и рутил примерно в равных концентрациях, а фазовый состав электровзрывного порошка $\mathrm{TiO}_{2}-\mathrm{EW}-73 \%$ анатаза и $27 \%$ рутила.

В зависимости от режимов последующей термообработки удавалось изменять соотношение этих фаз. Так, при отжиге синтезированных образцов $\left(\mathrm{TiO}_{2}-\mathrm{GC}\right)$ на воздухе при температуре выше $900^{\circ} \mathrm{C}$ формируется преимущественно рутил почти $100 \%$ с параметрами $a=4.5934 \AA, c=2.957 \AA$. При этом наблюдается замет- ное увеличение размера наночастиц (из данных ЭМ и $X$-ray средний размер блоков ОКР достигает $d \sim 60 \mathrm{~nm})$, сопровождающееся существенным уменьшением ширины рентгеновских линий.

3.3. Электронно-микроскопические дан ные образцов газофазного синтеза $\mathrm{TiO}_{2}-\mathrm{GC}$ и $\mathrm{TiO}_{2}$-EW после различных режимов термообработки. На рис. 2 (I-IV) представлены электронно-микроскопические снимки образцов газофазного синтеза $\mathrm{TiO}_{2}$-GC (рис. $\left.2(\mathrm{I}, a)\right)$ и электровзрывного $\mathrm{TiO}_{2}$-EW (рис. $2(\mathrm{I}, b)$ ) в исходном состоянии (разные 


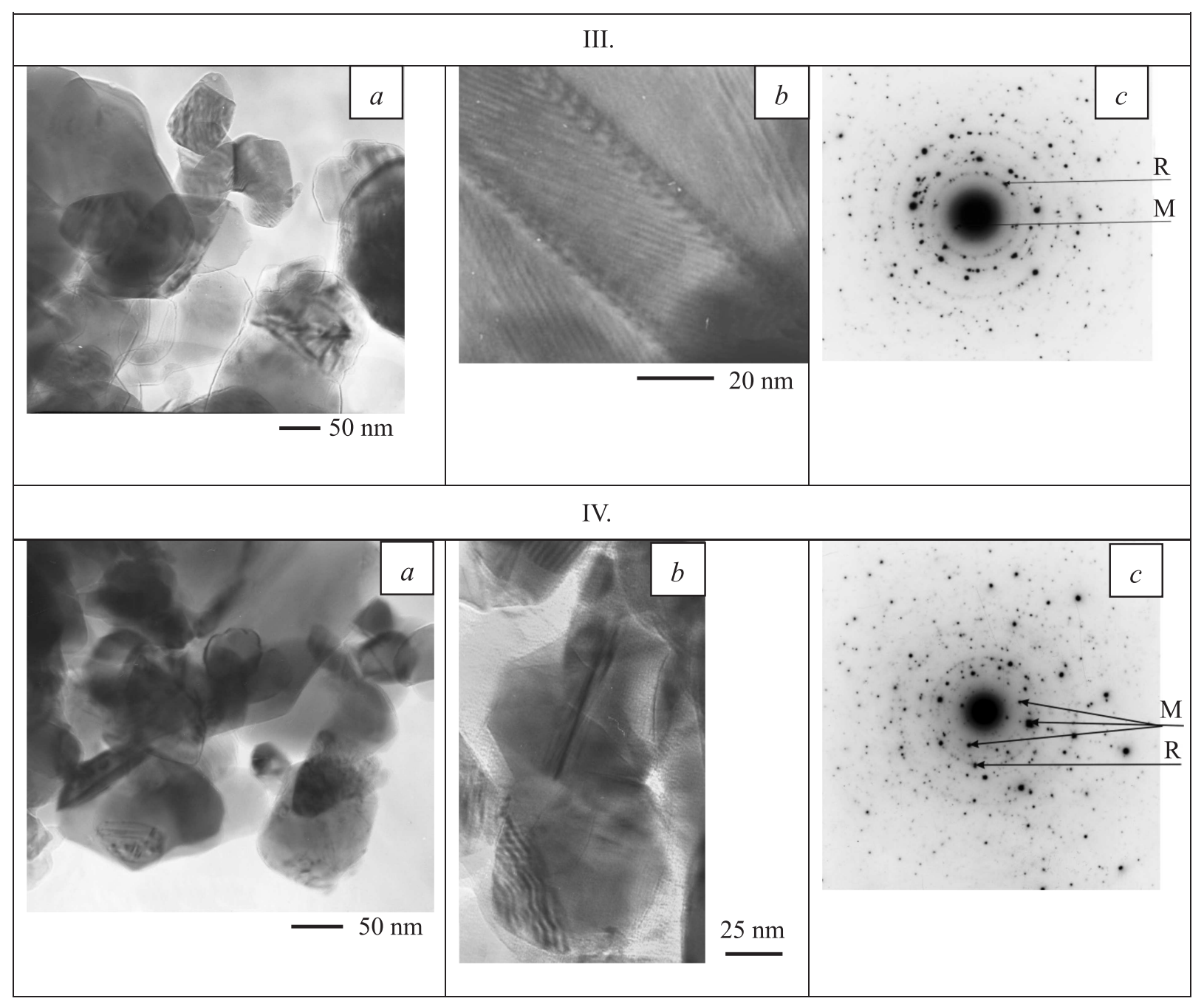

Рис. 2 (продолжение).

участки и разное увеличение), а также после отжига при $800^{\circ} \mathrm{C}$ (рис. $2(\mathrm{II})$ ), $900^{\circ} \mathrm{C}$ (рис. 2 (III)) в вакууме и последующего измельчения после обработки $900^{\circ} \mathrm{C}$ в агатовой ступке (рис. 2 (IV)). Для сравнения на рис. (рис. $2(\mathrm{I}, b)$ ) приведен ЭМ-снимок исходного электровзрывного образца $\left(\mathrm{TiO}_{2}-\mathrm{EW}\right)$ сразу после синтеза.

ЭМ-данные (см. данные на рис. $2(\mathrm{I}, a))$, полученные сразу после газофазного синтеза (исходное состояние) свидетельствуют об относительно узком гранулометрическом составе наночастиц диоксида титана со средним размером частиц около $20 \mathrm{~nm}$, максимальный размер наночастиц не превышает $40 \mathrm{~nm}$. Аналогично выглядит и образец $\mathrm{TiO}_{2}-\mathrm{EW}$ синтеза в исходном состоянии (рис. $2(\mathrm{I}, b))$, отличие состоит в том, что средний размер и дисперсия наночастиц $\mathrm{TiO}_{2}$-EW электровзрывного нагружения больше (от 10 до $100 \mathrm{~nm}$ ), чем для нанопорошков газофазного синтеза. Как указывалось выше, фазовый состав зависит от режимов синтеза, в частности от концентрации кислорода в аргоне. На электронограммах исходного образца $\mathrm{TiO}_{2}-\mathrm{GC}$ (рис. $2(\mathrm{I}, c)$ ) регистрируются линии рутила и анатаза. Контур частиц в исходном состоянии (рис. $2(\mathrm{I}, a)$ ) достаточно четкий, что свидетельствует об однородном поверхностном состоянии наночастиц. После отжига при $900^{\circ} \mathrm{C}$ размер частиц $\mathrm{TiO}_{2}-\mathrm{GC}$ синтеза увеличивается в среднем до $60 \mathrm{~nm}$, частицы приобретают более выраженную огранку (рис. 2 (III, $a)$ ) по сравнению с исходным состоянием с сохранением фаз Магнели [41].

На рис. 2 (II, $a, b)$ представлены картины высокоразрешающей электронной микроскопии (ВРЭМ) с различных участков образца $\mathrm{TiO}_{2}-\mathrm{GC}$, подвергнутого отжигу при $800^{\circ} \mathrm{C}$ в вакууме в течение $30 \mathrm{~min}$. Аналогичные картины наблюдаются и при отжиге в вакууме при $900^{\circ} \mathrm{C}, 30 \mathrm{~min}$ (рис. 2 (III, $\left.a, b\right)$. На снимках (см. рис. 2 (II, III), после отжига при $800^{\circ} \mathrm{C}$ и $900^{\circ} \mathrm{C}$, разные участки $a, b)$ отчетливо демонстрируются характерные для фаз Магнели $\mathrm{Ti}_{n} \mathrm{O}_{2 n-1}$ (в структуре рутила фазы $\mathrm{Ti}_{4} \mathrm{O}_{7}$ ) особенности в виде сложных чередующихся протяженных дефектов. Дефекты - кристаллографические сдвиги плоскостей (CS), содержащие локально 
в ближнем окружении разную концентрацию катионов $\mathrm{Ti}^{3+}$ и $\mathrm{Ti}^{4+}$, включая их упорядочение, хорошо описаны в литературе [42-46]. Фазы Магнели часто наблюдаются в массивных образцах $\mathrm{TiO}_{2}$ при относительно слабом отклонении состава оксида титана с фазой рутила от стехиометрии. На электронограммах обнаружены дополнительные рефлексы, соответствующие большим параметрам решетки, равным $6.2 \AA$ (рис. 2 (II, $c$ и III, $c)$ ), которые предположительно, исходя из измеренного параметра решетки, могут быть отнесены к фазам Магнели на основе $\mathrm{Ti}_{4} \mathrm{O}_{7}$. На рис. 2 (IV) приведены ЭМ снимки и электронограммы после истирания в ручной агатовой ступке нанокристаллических образцов $\mathrm{TiO}_{2}$, предварительно отожженных при $900^{\circ} \mathrm{C}$. Состояние поверхности образцов после растирания в ступке практически не изменилось, наблюдаются такие же особенности, как и для отожженных образцов. Очевидно, увеличилась концентрация контактирующих наночастиц. Показано, что при этом сохраняются дефекты, типичные для фаз Магнели в фазе рутила $\mathrm{TiO}_{2}$. Аналогичные структуры (фазы Магнели на основе $\mathrm{Ti}_{4} \mathrm{O}_{7}$ ) были обнаружены авторами работы [25] при исследовании наночастиц $\mathrm{TiO}_{2}$, при этом авторы полагают, что существует прямая корреляция между нестехиометрическим составом диоксида титана и, следовательно, концентрацией фаз Магнели (типа $\mathrm{Ti}_{4} \mathrm{O}_{7}$ ) и намагниченностью и, по их мнению, это единственный источник магнетизма. Кажется, действительно нельзя исключать обменное взаимодействие между носителями магнитного момента $\mathrm{Ti}^{3+}$ в этих полосах с учетом делокализованного состояния электронов в этих протяженных дефектах $[47,48]$. Однако расчеты, выполненные в работе [49] по магнитному состоянию фазы Магнели на основе $\mathrm{Ti}_{4} \mathrm{O}_{7}$, демонстрируют, что в указанных фазах может формироваться только низкотемпературная антиферромагнитная фаза. Кроме того, следует отметить принципиальный факт, что фазы Магнели формируются только в рутильной фазе, а магнитное состояние с ферромагнитным вкладом реализуется как в рутильной, так и в анатазной фазе. Упорядоченный характер дефектов может оказать сильное влияние на магнитные свойства $\mathrm{TiO}_{2}$ в любой структурной модификации. К числу таких особенностей можно отнести локализацию точечных дефектов (вакансий) и их упорядочение в приповерхностных слоях наночастиц $\mathrm{TiO}_{2}$ со структурой рутила, описанных в работе [25], которые также могут обеспечить появление магнитоупорядоченного состояния. Однако обнаружить эти структурные особенности в наносостоянии из-за отсутствия надежных адекватных структурных методов крайне сложно.

Таким образом, фазы Магнели не являются источниками магнетизма, и следует рассматривать другие дефекты, расположенные преимущественно на поверхности наночастиц в нанокристаллических нестехиометрических диоксидах титана независимо от фазового состава, такие как анионные вакансии и носители магнитного момента, например $\mathrm{Ti}^{3+}$ и $3 d$-примеси.
Таким образом, нельзя исключать из рассмотрения поверхностные дефекты как источник магнетизма в указанных оксидах. Как будет показано ниже, магнитные свойства образцов существенно изменяются в зависимости от режимов восстановительной обработки. Это также свидетельство того, что магнитные свойства образцов в значительной степени определяются особенностями структурного состояния поверхности наночастиц оксида и их дефектным исходным состоянием, а не только концентрацией указанных протяженных дефектов в объеме наночастиц $\mathrm{TiO}_{2}$, тем более что некоторые из них не дают ферромагнитного вклада, а приводят только к парамагнетизму или антиферромагнетизму при низких температурах.

3.4. Магнитное состояние диоксида титана после термообработок в вакууме и водороде. Магнитные свойства диоксидов титана в наносостоянии оказались очень чувствительными к режиму и методу синтеза и последующим термообработкам. Заметное отличие свойств и кривых намагничивания наблюдается в зависимости от того, в какой среде (отжиг в вакууме или в среде водорода), при какой температуре, с какой промежуточной термообработкой и с какой скоростью нагреваются образцы до высокой температуры. Имеет существенное значение и степень вакуума, определяющая скорость окислительновосстановительных реакций в процессе отжига образцов.

Детальное исследование магнитных свойств проведено на образце $\mathrm{TiO}_{2}$, синтезированного методом электровзрывного нагружения $\left(\mathrm{TiO}_{2}-\mathrm{EW}\right)$ и газофазного синтеза $\left(\mathrm{TiO}_{2}-\mathrm{GC}\right)$. Образцы $\mathrm{TiO}_{2}-\mathrm{EW}$ и $\mathrm{TiO}_{2}-\mathrm{GC}$ подвергались восстановительной обработке (отжиг в вакууме при $900^{\circ} \mathrm{C}$ в течение $0.5 \mathrm{~h}$, или в среде водорода при $900^{\circ} \mathrm{C}$ (образец $\mathrm{TiO}_{2}-\mathrm{EW}(1)$ ). Также проводилась двухступенчатая обработка - предварительный нагрев до $550^{\circ} \mathrm{C}$ в вакууме (с целью обезгаживания и дегидроксилирования) с последующей обработкой в среде водорода при $900^{\circ} \mathrm{C}, 0.5 \mathrm{~h}$ (образец $\mathrm{TiO}_{2}-\mathrm{EW}(2)$ ). Существование гидроксильных групп может быть дополнительным источником появления спонтанного магнитного момента в диоксиде титана [50]. Заметно бо́льшая величина магнитного момента и выраженное насыщение, получаемые без предварительного прогрева образцов сразу после обработки при $900^{\circ} \mathrm{C}$ в вакууме или в среде водорода (одноступенчатая обработка), возможно, вызваны дополнительными источниками магнетизма, связанными, например, с существованием гидроксильных групп. Именно поэтому в работе проводился сравнительный анализ магнитных свойств образцов, например под воздействием компактирующих обработок, предварительно испытавших различные термообработки (одноступенчатый (образец $\left.\mathrm{TiO}_{2}-\mathrm{EW}(1)\right)$ и двухступенчатый (образец $\left.\mathrm{TiO}_{2}-\mathrm{EW}(2)\right)$ отжиги), целью которого было удаление гидроксильных групп.

На рис. 3 приведены характерные кривые намагничивания образца $\mathrm{TiO}_{2}-\mathrm{GC}(1)$ и образцов $\mathrm{TiO}_{2}-\mathrm{EW}(1)$, 


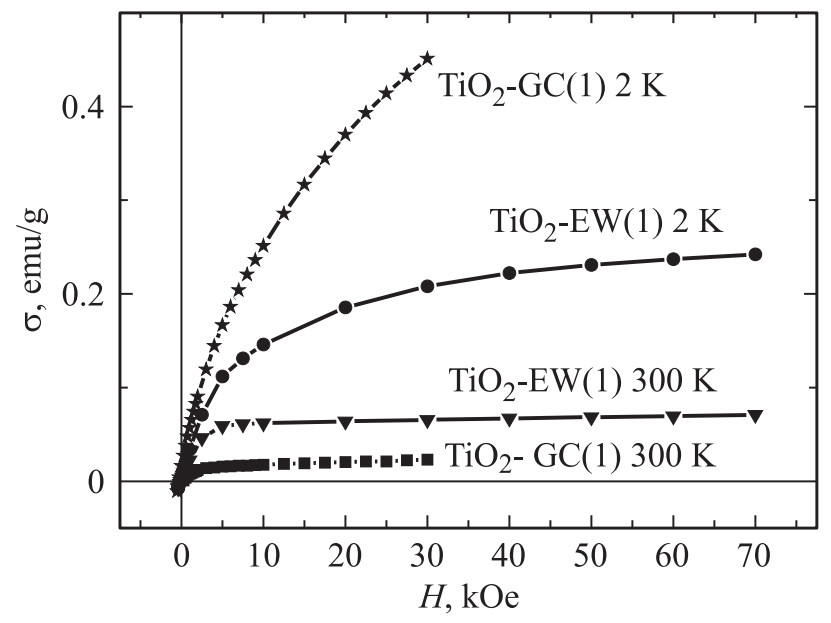

Рис. 3. Кривые намагничивания образцов $\mathrm{TiO}_{2}-\mathrm{GC}(1)$ и $\mathrm{TiO}_{2}-\mathrm{EW}(1)$, измеренные при 2 и $300 \mathrm{~K}$.

измеренные при $2 \mathrm{~K}$ и $300 \mathrm{~K}$. Качественно процесс намагничивания образца при разных температурах заметно отличается. Образец газофазного синтеза $\mathrm{TiO}_{2}-\mathrm{GC}(1)$, измеренный при $2 \mathrm{~K}$, имеет максимальное значение намагниченности, которое не достигает насыщения в полях при 3 Т. Вероятно, существенно бо́льшая величина намагниченности образца $\mathrm{TiO}_{2}-\mathrm{GC}(1)$, по сравнению с образцами $\mathrm{TiO}_{2}$-EW(1) при низкой температуре, связана предположительно с большей концентрацией парамагнитных ионов $\mathrm{Ti}^{3+}$ и низкой концентрацией кислородных вакансий в парамагнитном состоянии. В результате после вакуумной обработки вакансии и ионы $\mathrm{Ti}^{3+}$, ответственные за появление спонтанного магнитного момента, дают относительно небольшой вклад в спонтанный магнитный момент при комнатной температуре по сравнению с образцом $\mathrm{TiO}_{2}-\mathrm{EW}(1)$ (ср. на рис. 3 намагниченность $\mathrm{TiO}_{2}-\mathrm{GC}(1)$ и образца $\left.\mathrm{TiO}_{2}-\mathrm{EW}(1)\right)$.

При комнатной температуре для образцов $\mathrm{TiO}_{2}-\mathrm{EW}(1)$ после обработок наблюдается относительно легкое намагничивание с отчетливым насыщением и небольшим парапроцессом, напротив, при низкой температуре $(2 \mathrm{~K})$ наблюдается более заметное насыщение по сравнению с образцом $\mathrm{TiO}_{2}-\mathrm{GC}(1)$ при $2 \mathrm{~K}$.

Итак, вид кривых намагничивания свидетельствует, что образцы содержат различные магнитные вклады парамагнитный вклад от матрицы (слабо зависящий от температуры), от парамагнитных ионов титана $\mathrm{Ti}^{3+}$ (типа Кюри), а также вклад со спонтанной намагниченностью. Подробно были исследованы образцы, полученные EW методом, демонстрирующие более высокий спонтанный магнитный момент при комнатной температуре. Парамагнитный вклад типа Кюри для образцов $\mathrm{TiO}_{2}-\mathrm{EW}(1)$ и $\mathrm{TiO}_{2}-\mathrm{EW}(2)$ удовлетворительно описывается функцией Бриллюэна, в предположении, что локализованные моменты имеют спин $S=1 / 2$ и обусловлены существованием ионов $\mathrm{Ti}^{3+}$, вызванных появлением вакансий в кислородной подрешетке. Кри- вые намагничивания удается линеаризовать в диапазоне температур от 40 до $300 \mathrm{~K}$, анализ которых и позволил вычислить как парамагнитный вклад типа Кюри, так и определить компоненту со спонтанным магнитным моментом, которая для нас представляет основной интерес. Экстраполированная величина спонтанного магнитного момента для образца $\mathrm{TiO}_{2}-\mathrm{EW}(1)$ составляет около $0.086 \mathrm{emu} / \mathrm{g}$ при температуре $2 \mathrm{~K}$ и около $0.06 \mathrm{emu} / \mathrm{g}$ при комнатной температуре, а для образца $\mathrm{TiO}_{2}-\mathrm{EW}(2)$, испытавшего двухступенчатую обработку, эта величина равна $0.06 \mathrm{emu} / \mathrm{g}$ при $2 \mathrm{~K}$ и $0.03 \mathrm{emu} / \mathrm{g}$ при комнатной температуре. Экстраполированная величина спонтанного вклада при комнатной температуре для образца $\left(\mathrm{TiO}_{2}-\mathrm{GC}(1)\right)$ составляет величину около $0.067 \mathrm{emu} / \mathrm{g}$, a существенный вклад при $2 \mathrm{~K}$ обусловлен в основном парамагнитной компонентой типа Кюри. После отжига образцов на воздухе концентрация ферромагнитной фазы (F) не превышает $\sim 0.0002 \mathrm{wt} . \%$, а парамагнитный вклад Кюри (C) составляет величину на уровне $\leq 0.02$ at.\%. Таким образом, восстановительный отжиг образцов $\mathrm{TiO}_{2}-\mathrm{EW}(1)$ и $\mathrm{TiO}_{2}-\mathrm{EW}(2)$ в водороде или в вакууме приводит к росту концентрации как $\mathrm{F}$, так и парамагнитной компоненты Кюри $(\mathrm{C})$ до уровня $\sim 0.1 \mathrm{wt} . \%$. Восприимчивость всей системы существенно зависит от содержания $\mathrm{F}$ и $\mathrm{C}$ компонент, и выполненный анализ позволяет оценить восприимчивость чистого материала $\mathrm{TiO}_{2}$, которая составляет $5 \cdot 10^{-8} \mathrm{~cm}^{3} / \mathrm{g}$, что близко к табличным данным для массивного состояния.

Как уже обсуждалось, основная причина появления спонтанного магнитного момента (F) связана, например, с возникновением кислородных вакансий, межузельных атомов титана на поверхности частиц с учетом их упорядочения или других дефектов (например, линейных фаз Магнели) и изменением магнитного состояния в них, в частности появлением трехвалентного титана и возможного обменного взаимодействия между ними. Обнаружение спонтанного магнитного момента в нанокристаллических нанопорошках $\mathrm{TiO}_{2}$ со структурой анатаза доказывает существенную роль других типов дефектов, кроме фаз Магнели. На рис. 4 приведены кривые намагничивания порошков ST-21 (Ishihara Co.) после водородной обработки $\left(4.8 \mathrm{bar} \mathrm{H}_{2}, 700^{\circ} \mathrm{C}\right.$ в течение $2 \mathrm{~h}$ и последующего отжига в вакууме при $700^{\circ} \mathrm{C}$ в течение $4 \mathrm{~h}$, после которых, по данным ЭМ, сохраняется структура анатаза $(100 \%))$.

На рис. 4 после водородной обработки образца ST-21 наблюдается относительно высокая величина удельной намагниченности при комнатной температуре, равная примерно $0.03 \mathrm{emu} / \mathrm{g}$. Эта величина намагниченности уменьшается после двухнедельной выдержки образца на воздухе до величины намагниченности около $0.02 \mathrm{emu} / \mathrm{g}$. Снижение намагниченности может быть связано с уменьшением концентрации вакансий при взаимодействии образца с кислородом воздуха. Характер кривой намагничивания образца до и после выдержки ST-21 близок к ланжевеновскому или „квазисуперпарамагнитному“ типу. 


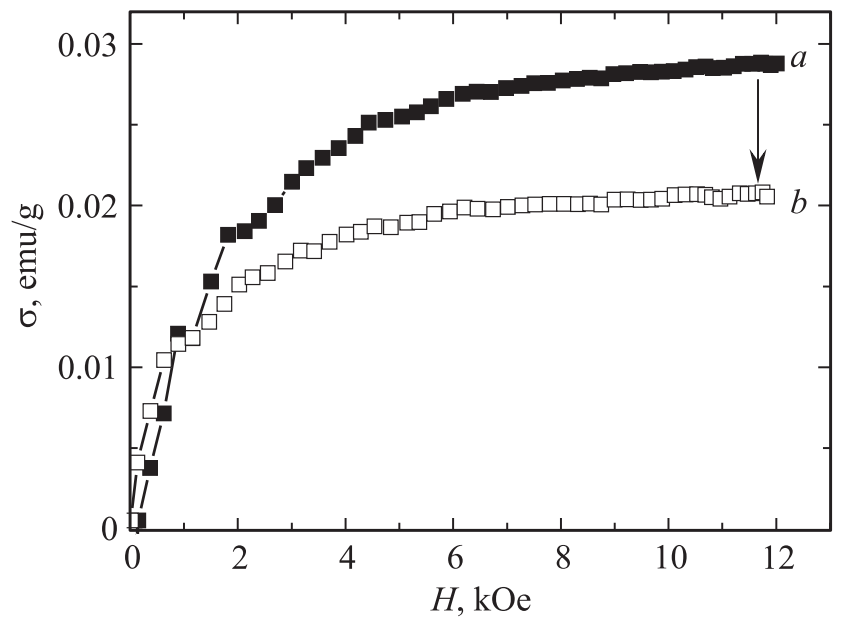

Рис. 4. Кривые намагничивания образца (ST-21) со структурой анатаза после отжига образца в водороде $\left(4.8 \mathrm{bar} \mathrm{H}_{2}, 700^{\circ} \mathrm{C}\right.$, $2 \mathrm{~h}+700^{\circ} \mathrm{C}$, в вакууме $\left.4 \mathrm{~h}\right)(a)$. Выдержка образца на воздухе в течение 15 дней приводит к снижению намагниченности $(b)$.

Эти результаты по исследованию магнитного состояния $\mathrm{TiO}_{2}$ в анатазной фазе после термообработки, очевидно, также демонстрируют принципиальную роль поверхностных дефектов и возможных поверхностных магнитных состояний и полностью исключают влияние локализованных в объеме линейных фаз Магнели на магнетизм $\mathrm{TiO}_{2}$.

Все примеси $3 d$-металлов, находясь в решетке $\mathrm{TiO}_{2}$ (растворы внедрения или замещения) в окисленном состоянии, могут давать дополнительный вклад (если имеют магнитный момент), наряду с другими носителями магнитного момента. Они точно также будут участвовать как в формировании парамагнитного вклада, так и состояний с неоднородным типом магнитного порядка. Анализ результатов как наших исследований, так и литературных данных демонстрирует, что в исследуемых системах этот вклад имеется, но он не является определяющим в нашем случае. Отжиг в кислороде воздуха при $900^{\circ} \mathrm{C}$ снижает не только концентрацию вакансий и, следовательно, концентрацию парамагнитных центров, но и спонтанный магнитный момент, что сопровождается почти полным отсутствием вклада со спонтанной намагниченностью после указанной обработки.

3.5. Явление Exchange Bias в нанокристаллических по рошках $\mathrm{TiO}_{2}$. Подчеркнем, что для нас особый интерес представляет появление и описание в нанокристаллических порошках $\mathrm{TiO}_{2}$ вклада со спонтанной намагниченностью, природа которого и его локализация до сих пор остается предметом дискуссий. Описать единым образом кривые намагничивания, например в рамках модели для суперпарамагнитного поведения, в указанной области температур не удается. Это означает, что необходимо использовать другие подходы для описания процесса намагничивания, например с использованием модели перемагничивания неколлинеарных спиновых конфигураций [26-28], образующихся в нашем случае на поверхности дефектных наночастиц $\mathrm{TiO}_{2}$. В этом случае предполагается существование набора различных магнитных спиновых состояний (ферро-, антиферрои неколлинеарных структур), возможно, разделенных по полям перемагничивания относительно небольшим барьером.

Одно из следствий этого заключения состоит в том, что при сосуществовании гетерогенного магнитного состояния (например, антиферромагнитной (AF) и ферромагнитной (F) фаз) можно ожидать сдвинутой петли гистерезиса (exchange bias) при охлаждения образца в магнитном поле. Сандвич, состоящий из $\mathrm{AF}$ и $\mathrm{F}$ фаз, в результате обменного взаимодействия между ними приводит к смещенной петле гистерезиса при охлаждении в поле от высокой температуры с обязательным условием существования анизотропного вклада в AF подсистеме (или, другими словами, используемой в литературе, обменной жесткости в антиферромагнетике) [51-53]. В частности, поверхностная анизотропия может давать требуемый вклад [54-56].

На рис. 5 представлены кривые размагничивания образцов $\mathrm{TiO}_{2}$, полученных газофазным синтезом $\left(\mathrm{TiO}_{2}-\mathrm{GC}(1)\right)$ и электровзрывным нагружением $\left(\mathrm{TiO}_{2}-\mathrm{EW}(1)\right)$, при их охлаждении от 300 до $2 \mathrm{~K}$ в поле 3 и 5 Т соответственно. Наблюдается сдвиг петли гистерезиса (см. вставки на рис. 5) как вдоль оси полей, так и по оси ординат для обоих образцов. Так, величина сдвига для образца $\mathrm{TiO}_{2}-\mathrm{GC}(1)$ по $H_{c}$ составляет более $80 \mathrm{Oe}\left(H_{c}\right.$ на нисходящей ветви петли гистерезиса равна 320 Ое, а на восходящей $237 \mathrm{Oe}$ ), а по остаточной индукции разница составляет около $0.001 \mathrm{emu} / \mathrm{g}$. Для образца $\mathrm{TiO}_{2}-\mathrm{EW}(1)$ разница в $H_{c}$ меньше, но хорошо

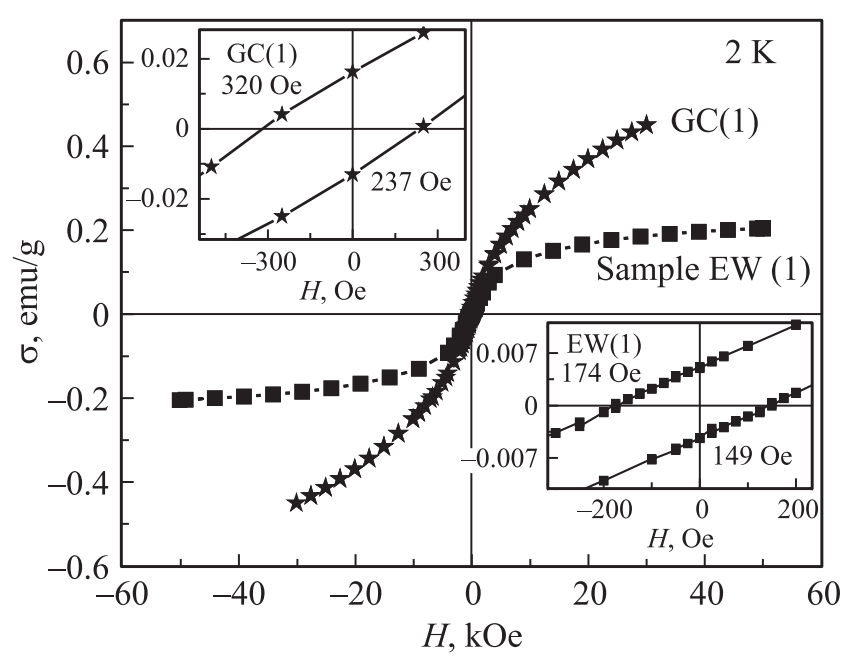

Рис. 5. Кривые намагничивания и перемагничивания образца $\mathrm{TiO}_{2}-\mathrm{GC}(1)$ и образца $\mathrm{TiO}_{2}-\mathrm{EW}(1)$, полученные в режиме field cooled (FC) - охлаждение в поле 3 T от комнатной температуры до температуры $2 \mathrm{~K}$. На вставках кривые намагничивания и размагничивания образцов $\mathrm{GC}(1)$ и $\mathrm{EW}(1)$ в малых полях, охлажденных в режиме FC, демонстрирующие сдвиг петли гистерезиса. 
регистрируется и равна около 25 Ое. Смещенные петли гистерезиса приведены для обоих образцов на вставках к рис. 5. Также следует отметить, что величины намагниченности, измеренные в положительных и отрицательных полях при 3 и 5 Т для указанных образцов совпадают. Это означает, что образцы уже в поле $3 \mathrm{~T}$ насыщаются и таким образом можно утверждать, что сдвиг петли гистерезиса не связан с неполным намагничиванием системы до насыщения или частным циклом петли гистерезиса. Таким образом, мы должны полагать, что это является следствием однонаправленной обменной анизотропии как результат сосуществования в нанокристаллическом $\mathrm{TiO}_{2}$ разных магнитных структур (например, $\mathrm{AF}$ и $\mathrm{F}$ типа) со сравнимым объемным вкладом; при этом в структуре с предпочтительным антиферромагнитным упорядочением неизбежно должна быть относительно высокая анизотропия, чтобы обеспечить наблюдаемый сдвиг петли гистерезиса при охлаждении образца в магнитном поле от 300 до 2 К. Гипотетическая температура Нееля областей с „антиферромагнитным“ упорядочением может быть ниже или близка к температуре Кюри ферромагнитной фазы, чтобы обеспечить эффективное взаимодействие с ферромагнитными областями при охлаждении образца от комнатной температуры. Эту температуру определить не удалось, исследуя сдвиг петли гистерезиса при охлаждении в поле от разных температур, сдвиг петли наблюдался в диапазоне от 100 до $20 \mathrm{~K}$. Возможно, эта температура ниже, чем $20 \mathrm{~K}$.

Также важно отметить, что магнитные состояния в $\mathrm{TiO}_{2}$ проявляют гистерезисные свойства, которые зависят от температуры измерения. Так, коэрцитивная сила образца $\mathrm{TiO}_{2}-\mathrm{EW}(1)$ изменяется от 80 Ое почти до $200 \mathrm{Oе}$ при комнатной и температуре $2 \mathrm{~K}$ соответственно. Остаточная намагниченность в указанной области температур также увеличивается более, чем в 2 раза при снижении температуры от комнатной до 2 К. В рамках модели суперпарамагнетизма объяснить сдвиг петли гистерезиса и наличие коэрцитивной силы невозможно. Итак, смещение петли гистерезиса при низкой температуре, наличие коэрцитивной силы при комнатной температуре свидетельствует не только о гетерогенном магнитном состоянии с различным типом магнитного порядка, но и об эффективном взаимодействии между ними. Значительную величину $H_{c}$ при комнатной температуре, вероятно, можно объяснить более или менее непротиворечиво, полагая существование эффективного фрустрированного обменного взаимодействия между областями с различным спиновым порядком, сохраняющимся при температуре даже выше комнатной с учетом анизотропного вклада.

Итак, суммируя результаты проведенного анализа, можно сделать следующее общее заключение, в существенной мере совпадающее с уже высказанными идеями. Появление парамагнетизма (парамагнитных центров) при определенных обработках является результатом появления дефектов, таких как дефекты вакансионного типа по кислородной подрешетке, межузельных атомов или ионов носителей магнитного момента, например, из-за изменения валентного состояния катионов, включая некоторый вклад от примесей $3 d$-металлов. Существование фаз Магнели (например, $\mathrm{Ti}_{4} \mathrm{O}_{7}$ ) не может объяснить вклад в ферромагнитное упорядочение в нано- $\mathrm{TiO}_{2}$ с фазой рутила. Обнаружение ферромагнетизма в структуре анатаза приводит к необходимости рассматривать также другие дефекты, локализованные, например, на поверхности наночастиц, которые могут быть определяющими в наносостоянии, независимо от фазового состояния $\mathrm{TiO}_{2}$ как в рутильной, так и в анатазной фазе.

Усиление парамагнитного вклада в матрице $\mathrm{TiO}_{2}$ при некоторых обработках связано преимущественно с ростом концентрации дефектов и в меньшей степени с наличием примеси, но ее также нельзя полностью исключать. Рост парамагнитного вклада (типа Кюри) может быть замечательной количественной характеристикой уровня дефектности в сплаве при разных обработках. Одновременно это индикатор и предвестник формирования различных спиновых конфигураций, особенно при скоплении этих центров в локальной области. Увеличение концентрации таких центров на поверхности и их возможное упорядочение может привести к фрустрированным обменным взаимодействиям из-за структурных неоднородностей поверхности (разная координация атомов, другие межатомные расстояния, дефекты разного типа и т.п.) и реализации гетерогенных магнитных состояний.

Таким образом, мы гипотетически допускаем существование поверхностных магнитных неоднородностей, природа которых может быть связана с реализацией различных спиновых конфигураций на поверхности наночастиц, обусловленной фрустрированными обменными взаимодействиями между носителями магнитного момента как результат преимущественно дефектного поверхностного состояния нестехиометрического $\mathrm{TiO}_{2}$ в нанокристаллическом состоянии. Наличие сдвига петли гистерезиса указывает на существование гетерогенного магнитного состояния. Удаление кислородных вакансий и других дефектов при отжиге в воздушной среде устраняет основную причину появления носителей магнитного момента, а вид кривой намагничивания с низкой величиной намагниченности становится похожим на парамагнитное поведение обычного стехиометрического диоксида титана.

\section{4. Влияние компактирования на магнитные свойства $\mathrm{TiO}_{2}$}

Несмотря на большой интерес исследователей к проблеме взаимодействий частиц с необычными поверхностными свойствами, начиная с работы [28], авторы которой впервые обратили внимание на особые магнитные свойства поверхности наночастиц, мы должны 
заметить, что экспериментальных исследований, свидетельствующих о принципиальной важности проблемы нанокристаллического состояния и ее общности, все еще крайне мало, а на нанокристаллических образцах $\mathrm{TiO}_{2}$ практически нет. Обсуждая свойства $\mathrm{TiO}_{2}$ в рамках модели неоднородных магнитных состояний на поверхности наночастиц, очевидно, можно предположить, что в результате обменного или диполь-дипольного взаимодействия контактирующих областей и увеличения концентрации взаимодействующих интерфейсов следует ожидать заметного изменения состояния намагниченности при их контакте. При этом можно ожидать, из-за фрустрированного характера взаимодействий, как усиление ферромагнитного вклада, так и, возможно, антиферромагнитных взаимодействий.

4.1. Магнитные свойства нанокристаллического $\mathrm{TiO}_{2}$ в фазе рутила после компакти р о в ания. При изучении влияния компактирующей обработки нанопорошков на магнитные свойства диоксида титана в рутильной фазе нами было установлено, что растирание нанопорошка в ступке или компактирование в пресс-форме, в мягких условиях без пластической компоненты, сопровождается значительным ростом намагниченности, иногда в несколько раз. Рассмотрим более подробно некоторые результаты, полученные при исследовании влияния компактирования на структурные особенности $\mathrm{TiO}_{2}$ со структурой рутила. Электронномикроскопические исследования (рис. 2 (I, II, III, IV)) структурного состояния поверхности наночастиц оксида титана (образец $\mathrm{TiO}_{2}-\mathrm{GC}(1)$ в рутильной фазе) до и после деформации подтверждают отсутствие заметных изменений структуры как в объеме частиц, так и поверхностного слоя - формируются только новые контактирующие поверхности. По крайней мере у нас нет доказательств изменения структуры поверхности и ее дефектного состояния после таких обработок. Итак, в лучшем случае могут появиться дополнительные границы раздела между частицами при сохранении их размера с ростом компактирующего давления и увеличением удельной плотности образца. На рис. 6 приведены кривые намагничивания образца $\mathrm{TiO}_{2}-\mathrm{GC}$ после различных компактирующих обработок в ручной агатовой ступке и пресс-форме. Следует отметить несколько существенных экспериментальных результатов, представленных на рис. 6. Во-первых, после компактирования в титановой пресс-форме $(550 \mathrm{MPa})$ или ручного истирания порошка $\mathrm{TiO}_{2}\left(\mathrm{TiO}_{2}-\mathrm{GC}(1)\right.$ - фаза рутила) в агатовой ступке существенно возрастает намагниченность - так, после растирания в ступке более, чем в 3 раза, а во-вторых, характер кривой намагничивания остается качественно неизменным, увеличивается только доля вклада со спонтанной намагниченностью.

Качественно похожие явления наблюдаются и для нанокристаллического порошка $\mathrm{TiO}_{2}-\mathrm{EW}$, полученного EW методом, после соответствующих восстановительных и компактирующих обработок. На рис. 7 приведены кривые намагничивания порошка $\mathrm{TiO}_{2}-\mathrm{EW}(2)$, ил-

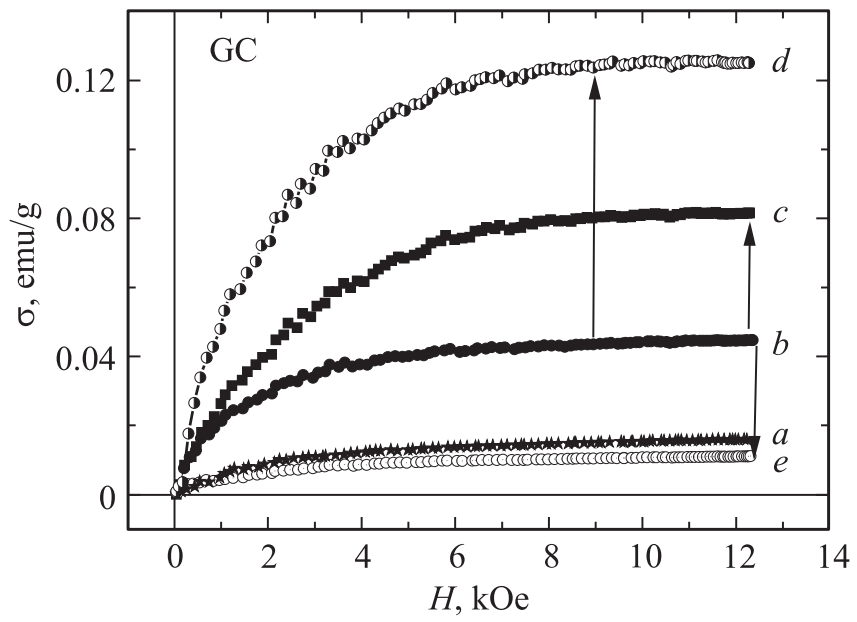

Рис. 6. Кривые намагничивания образца $\mathrm{TiO}_{2}-\mathrm{GC}$ после различных обработок (исходное состояние $\mathrm{TiO}_{2}-\mathrm{GC}(a)$ ); вакуумная обработка $900^{\circ} \mathrm{C}, 0.5 \mathrm{~h}\left(\mathrm{TiO}_{2}-\mathrm{GC}(1)\right)(b)$; последующее прессование $(c)$ и растирка в ступке $(d)$; и отжиг образца на воздухе при $700^{\circ} \mathrm{C}$ после обработки в вакууме при $900^{\circ} \mathrm{C}(e)$.

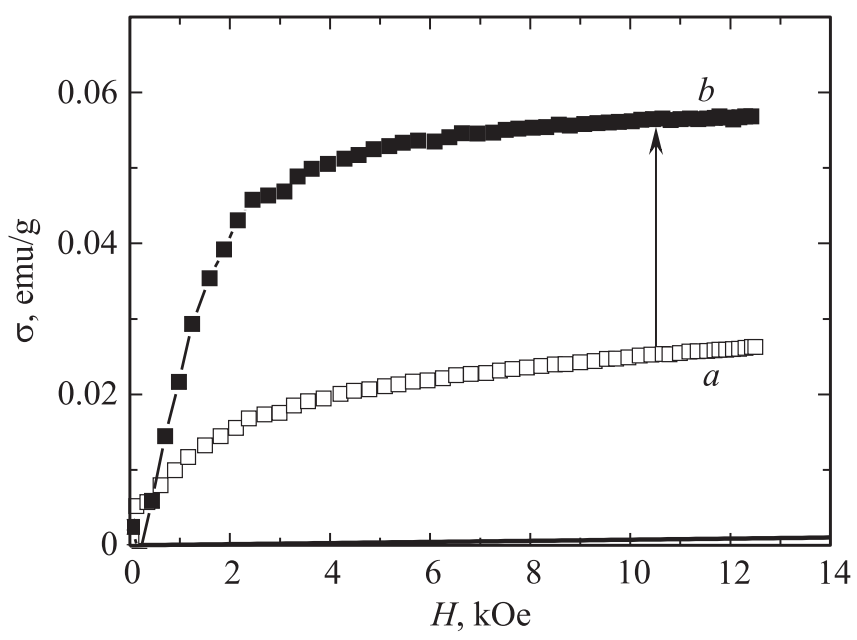

Рис. 7. Кривые намагничивания нанопорошка $\mathrm{TiO}_{2}-\mathrm{EW}(2)$ с фазой рутила (двухступенчатая обработка-откачка в вакууме при $550^{\circ} \mathrm{C}$, затем отжиг в среде водорода при $\left.900^{\circ} \mathrm{C}, 0.5 \mathrm{~h}\right)$ до $(a)$ и после компактирования в пресс-форме (550 MPa) $(b)$.

люстрирующие эффект влияния взаимодействия между наночастицами $\mathrm{TiO}_{2}$ на величину намагниченности. Как уже отмечалось, предварительный отжиг при $550^{\circ} \mathrm{C}$ проводился с целью дегазации и дегидроксилирования образца. Кривая намагничивания после двухступенчатой обработки характеризуется такой же нелинейной зависимостью в полях до $12 \mathrm{kOe}$ при комнатной температуре и примерно таким же значением удельной намагниченности, равной $0.026 \mathrm{emu} / \mathrm{g}$, как и для $\mathrm{TiO}_{2}-\mathrm{GC}(1)$ образца.

Как видно из рис. 7, намагниченность образца $\mathrm{TiO}_{2}$-EW(2) вырастает более, чем в 2 раза при компактировании. Нелинейный характер кривой намагничивания сохраняется, при этом наблюдается существенный 
рост намагниченности в малых полях, демонстрирующий рост вклада со спонтанной намагниченностью. При увеличении давления в матрице растет и величина намагниченности образца. Более высокое давление (около $50 \mathrm{~kg} / \mathrm{mm}^{2}$ ) при компактировании в прессформе приводит к большей концентрации границ раздела (интерфейсов) и, следовательно, к более высокой вероятности взаимодействия локализованных магнитных областей при их контакте, которое сопровождается ростом областей с ферромагнитным типом спинового порядка при их эффективном обменном или магнитостатическом взаимодействии. Эти результаты практически исключают роль ферромагнитных примесей в исходных порошках. Для ферромагнитных примесей, независимо от приложенного давления или способа компактирования, намагниченность не должна была бы столь сильно измениться.

Необходимо отметить еще один очень важный экспериментальный результат, состоящий в том, что эффект роста намагниченности после измельчения в ступке или компактирования наблюдается только для определенных исходных магнитных состояний нанопорошка. Так, компактирование исходного порошка сразу после синтеза с малой исходной величиной намагниченности и преимущественно парамагнитным вкладом практически не влияет на намагниченность $\mathrm{TiO}_{2}$ после компактирования. Предположительно, это состояние характеризуется низкой концентрацией парамагнитных центров. Как уже упоминалось, отжиг в высоком вакууме или в водороде при $900^{\circ} \mathrm{C}$ с предварительной обработкой, например при $550^{\circ} \mathrm{C}$ (двухступенчатая обработка образец $\left.\mathrm{TiO}_{2}-\mathrm{EW}(2)\right)$, увеличивает, как правило, намагниченность образцов в результате механизмов, упомянутых выше. При этом существенно вырастает намагниченность, которая в большинстве случаев описывается нелинейным поведением кривой намагничивания, как до компактирования или растирания в ступке, так и после обработки, т.е. не изменяет своего характера (см. рис. 7). Именно эти состояния демонстрируют значительный рост намагниченности по сравнению с исходными образцами после компактирования образцов.

Установлено, что эффект влияния компактировании или измельчения в ступке на изменение намагниченности образцов $\mathrm{TiO}_{2}$ также отсутствует и в том случае, когда образцы имеют высокую намагниченность с хорошо выраженным насыщением. Так, обработка исходного образца серии $\mathrm{TiO}_{2}-\mathrm{EW}(1)$ при $900^{\circ} \mathrm{C}, 0.5 \mathrm{~h}$ (в водороде или в вакууме (см. рис. 3) кривая намагничивания при комнатной температуре) приводит к формированию „ферромагнитного“ характера кривой намагничивания с насыщением, и последующее компактирование этого образца не приводит к изменению намагниченности. Точно также и из состояния с низкой намагниченностью, например после отжига образца в среде воздуха при температуре 700 или $900^{\circ} \mathrm{C}$, компактирование этого нанопорошка не изменяет его намагниченность, из-за отсутствия магнитных областей на поверхности наночастиц.

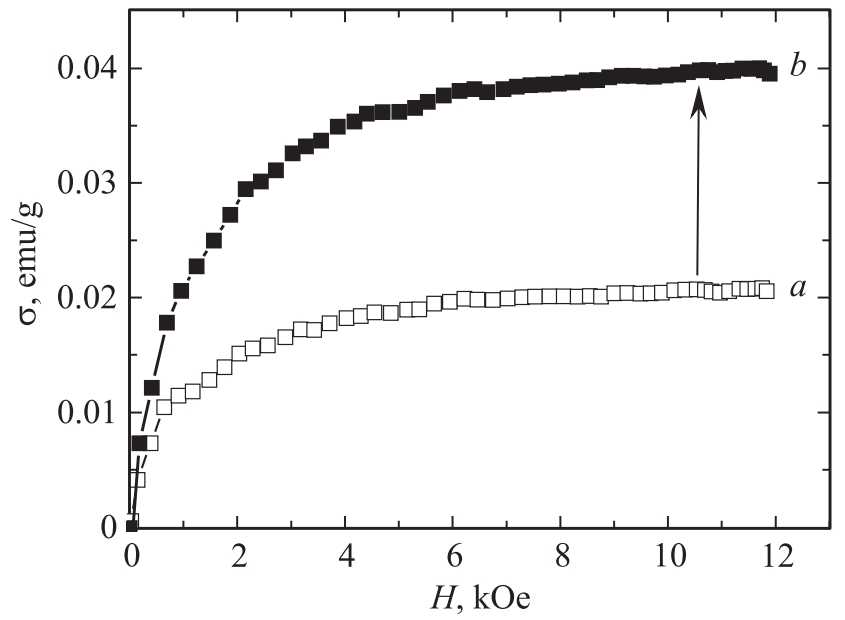

Рис. 8. Изменение намагниченности образца $\left(\mathrm{ST}-21+\mathrm{H}_{2}\right)$ с фазой анатаза $\left(\mathrm{H}_{2}, 5 \mathrm{bar}, 700^{\circ} \mathrm{C}, 2 \mathrm{~h}+\right.$ вакуум $700^{\circ} \mathrm{C}$, нагрев $4 \mathrm{~h})$ до $(a)$ и после его измельчения в агатовой ступке (ST$21+\mathrm{H}_{2}+$ grinding $\left.(b)\right)$ (см. также обработку и обозначения в таблице).

4.2. Магнитные свойства нанокристаллического $\mathrm{TiO}_{2}$ в фазе анатаза после компактирования. С целью выяснения влияния фазового структурного состояния $\mathrm{TiO}_{2}$ на свойства образцов, были проведены исследования магнитных свойств компактированных нанокристаллических порошков $\mathrm{TiO}_{2}$ (ST21) со структурой анатаза, в которой не формируются фазы Магнели.

На рис. 8 представлены результаты изучения магнитных свойств после компактирования этих образцов, подвергнутых водородным термообработкам в фазе анатаза, демонстрирующие эффект существенного влияния концентрации контактов между частицами на рост намагниченности и доказывающие преимущественную роль поверхностных дефектов, отличных от фаз Магнели, в формировании намагниченности. При этом, так же как и в случае фазы рутила, до и после компактирования, характер кривой намагничивания сохраняется, оставаясь нелинейным.

Итак, принципиальный факт состоит в том, что поверхностные дефекты формируют магнитные области с разным магнитным порядком на периферии наночастиц $\mathrm{TiO}_{2}$ независимо от структурного состояния, в котором они находятся, - в фазе рутила или анатаза и оказываются очень чувствительными к компактированию.

\section{5. Выводы}

1. Магнитные свойства образцов существенно зависят от предистории (метода синтеза) и последующих режимов термообработки в разных средах. В исходном состоянии после синтеза, как правило, образцы имеют парамагнитный вид кривой намагничивания, обусловленный существованием парамагнитных центров типа 
Кюри на фоне парамагнетизма матрицы $\mathrm{TiO}_{2}$, слабо зависящего от температуры.

2. Нагрев образцов при высокой температуре в вакууме в зависимости от степени вакуума, либо водородная обработка демонстрирует существенное увеличение как парамагнитного вклада, так и появление спонтанного магнитного момента в образцах. Рост намагниченности может быть связан с существованием большой концентрации структурных кислородных вакансий, присутствием $\mathrm{Ti}^{3+}$ и некоторой доли $3 d$-примесей.

3. Обнаруженные в наночастицах $\mathrm{TiO}_{2}$ со структурой рутила линейные фазы Магнели (предположительно на основе $\left.\mathrm{Ti}_{4} \mathrm{O}_{7}\right)$ и содержащие трехвалентные ионы титана не могут быть источниками ферромагнитного вклада без учета дефектов, например вакансий по анионной подрешетке. Установлен экспериментальный факт, состоящий в том, что поверхностные дефекты формируют магнитные области на периферии наночастиц $\mathrm{TiO}_{2}$, независимо от структурного состояния, в котором они находятся, - рутила или анатаза и оказываются очень чувствительными к компактированию.

4. Чувствительность магнитного состояния поверхности к компактирующей обработке (растирание в ступке или прессование) оказывается достаточно высокой (намагниченность возрастает более, чем в 2 раза) независимо от кристаллической структуры $\mathrm{TiO}_{2}$, что доказывает роль неоднородного магнитного состояния поверхности в формировании свойств нанокристаллического диоксида титана и преимущественную локализацию магнитных моментов в приповерхностных областях.

5. Показано, что для реализации роста намагниченности при компактировании требуется оптимальное исходное магнитное состояние, предпочтительно нелинейный „квазисуперпарамагнитный“ исходный вид кривой намагничивания. Компактирование образца в „квазисуперпарамагнитном“ состоянии позволяет заметно увеличить магнитный вклад, вероятно, в результате обменного взаимодействия областей с локализованными магнитными моментами на поверхности. Характер кривой намагничивания в этом случае сохраняется и остается существенно нелинейным. Компактирование образца после высокотемпературной обработки в вакууме или водороде при $900^{\circ} \mathrm{C}$, приводящей к выраженному „ферромагнитному“ упорядочению с насыщением, не изменяет намагниченность. Намагниченность после компактирования не изменяется и в том случае, если предварительно образец был отожжен в атмосфере воздуха или кислорода, что сопровождается отсутствием как парамагнитного состояния, так и областей с неоднородным намагничиванием в нанопорошках, что устраняет основную причину изменения свойств при последующем компактировании.

6. Основной вывод работы состоит в том, что дефектное состояние поверхности нанокристаллических оксидов (например, наличие вакансий по анионной подрешетке и других дефектов) оказывает доминирующее влияние на формирование магнитных свойств исследуемых образцов. Ключевое значение имеет локализация дефектов и носителей магнитного момента на поверхности, которые и определяют магнитные свойства нанопорошков. Установлено, что носители магнитного момента независимо от фазового состояния $\mathrm{TiO}_{2}$ локализованы преимущественно в приповерхностных областях наночастиц. На поверхности могут формироваться области с различным спиновым порядком, характер и тип магнитного упорядочения которых определяется сложными конкурирующими взаимодействиями на интерфейсах.

7. Доказательством существования в системе гетерогенного магнитного состояния является обнаружение сдвига петель гистерезиса при охлаждении образцов $\mathrm{TiO}_{2}-\mathrm{GC}(1)$ и $\mathrm{TiO}_{2}-\mathrm{EW}(1)$ в поле $(\mathrm{FC})$ от комнатной температуры до $2 \mathrm{~K}$. Это состояние является результатом сосуществования поверхностных нанообластей с различными спиновыми конфигурациями, например с АФ/спин-стекольным и ферромагнитным состоянием и сильным обменным взаимодействием между ними с учетом анизотропного вклада.

Мы признательны Ю.А. Котову (ИЭФ УрО РАН) за предоставленные образцы, синтезированные электровзрывным методом, научным сотрудникам ИФМ УрО РАН А.А. Мысику, В.С. Гавико, В.П. Пилюгину за помощь в подготовке образцов и их структурной аттестации.

\section{Список литературы}

[1] M. Venkatesan, C.B. Fitzgerald, J.M.D. Coey. Nature 430, 630 (2004).

[2] A. Sundaresan, C.N.R. Rao. Nano Today 4, 96 (2009).

[3] P. Dutta, M.S. Seehra, Y. Zhang, I. Wender. J. Appl. Phys. 103, 07D104 (2008).

[4] G. Han, S. Hu, S. Yan, L. Mei. Phys. Status Solidi (RRL) 3, 148 (2009)

[5] M. Stoneham. J. Phys.: Condens. Matter 22, 074211 (2010).

[6] C. Sudakar, P. Kharel, R. Suryanarayanan, J.S. Thakur, V.M. Naik, R. Naik, G. Lawes. J. Magn. Magn. Mater. 320, L31 (2008).

[7] N.H. Hong, J. Sakai, N. Poirot, V. Brizé. Phys. Rev. B 73, 132404 (2006).

[8] А.Е. Ермаков, М.А. Уймин, А.В. Королев, К.Н. Михалев, А.Н. Пирогов, А.Е. Теплых, Н.Н. Щеголева, В.С. Гавико, И.В. Бызов, В.В. Майков. ФТТ 57, 283 (2015).

[9] M. Grätzel. J. Photochem. Photobiol. A 164, 3 (2004).

[10] K. Yang, Y. Dai, B. Huang, Y.P. Feng. Phys. Rev. B 81, 033202 (2010).

[11] A.K. Rumaiz, B. Ali, A. Ceylan, M. Boggs, T. Beebe, S.I. Shah. Solid State Commun. 144, 334 (2007).

[12] S. Zhou, E. Čižmár, K. Potzger, M. Krause, G. Talut, M. Helm, J. Fassbender, S.A. Zvyagin, J. Wosnitza, H. Schmidt. Phys. Rev. B 79, 113201 (2009).

[13] М.А. Коротин, Н.А. Скориков, В.М. Зайнуллина, Э.З. Курмаев, А.В. Лукоянов, В.И. Анисимов. Письма в ЖЭТФ 94, 884 (2011).

[14] A.N. Morozovska, E.A. Eliseev, M.D. Glinchuk, R. Blinc. Physica B 406, 1673 (2011).

[15] F. Wang, Z. Pang, L. Lin, S. Fang, Y. Dai, S. Han. Phys. Rev. B 80, 144424 (2009). 
[16] M.K. Nowotny, L.R. Sheppard, T. Bak, J. Nowotny. J. Phys. Chem. C 112, 5275 (2008).

[17] D.J. Payne, E.A. Marquis. Chem. Mater. 23, 1085 (2011).

[18] S. Ghosh, G.G. Khan, K. Mandal, A. Samanta, P.M.G. Nambissan. J. Phys. Chem. C 117, 8458 (2013).

[19] B. Choudhury, A. Choudhury. J. Appl. Phys. 114, 203906 (2013).

[20] A. Sundaresan, C.N.R. Rao. Nano Today 4, 96 (2009).

[21] M. Wang, M. Feng, X. Zuo. Appl. Surf. Sci. 292, 475 (2014).

[22] B.B. Straumal, A.A. Mazilkin, S.G. Protasova, A.A. Myatiev, P.B. Straumal, G. Schütz, P.A. van Aken, E. Goering, B. Baretzky. Phys. Rev. B 79, 205206 (2009).

[23] R.H. Kodama, A.E. Berkowitz, E.J. McNiff, jr., S. Foner. Phys. Rev. Lett. 77, 394 (1996).

[24] R.H. Kodama, A.E. Berkowitz, E.J. McNiff, jr., S. Foner. J. Appl. Phys. 81, 5552 (1997).

[25] E. Tronc, A. Ezzir, R. Cherkaoui, C. Chanéac, M. Noguès, H. Kachkachi, D. Fiorani, A.M. Testa, J.M. Grenèche, J.P. Jolivet. J. Magn. Magn. Mater. 221, 63 (2000).

[26] H. Gleiter, Th. Schimmel, H. Hahn. Nano Today 9, 17 (2014).

[27] P. Yu, Y.H. Chu, R. Ramesh. Mater. Today 15, 320 (2012).

[28] J.M.D. Coey, Ariando, W.E. Pickett. MRS Bulletin 38, 1040 (2013).

[29] J. Mannhart, D.G. Schlom. Sci. 327, 1607 (2010).

[30] А.Е. Ермаков, М.А. Уймин, А.В. Королев, К.Н. Михалев, А.Н. Пирогов, А.Е. Теплых, Н.Н. Щеголева, В.С. Гавико, И.В. Бызов, В.В. Майков. ФТТ 157, 283 (2015).

[31] В.А. Цурин, А.Е. Ермаков, М.А. Уймин, А.А. Мысик, Н.Н. Щеголева, В.С. Гавико, В.В. Майков. ФТТ 56, 287 (2014).

[32] Ю.А. Котов, А.В. Багазеев, И.В. Бекетов, А.М. Мурзакаев, О.М. Саматов, А.И. Медведев, Н.И. Москаленко, О.Р. Тимошенкова, Т.М. Демина, А.К. Штольц. ЖТФ 75, 39 (2005).

[33] В.Б. Выходец, Т.Е. Куренных, А.Е. Ермаков, И.В. Бекетов, А.В. Багазеев, В.С. Гавико, М.В. Кузнецов, А.И. Медведев, М.А. Уймин, К.И. Шабанова, Н.Н. Щеголева. Рос. нанотехнологии 8, 57 (2013).

[34] X. Yu, Z. Zhan, J. Rong, Z. Liu, L. Li, J. Liu. Chem. Phys. Lett. 600, 43 (2014).

[35] J. Bisquert, F. Fabregat-Santiago, I. Mora-Sero, G. GarciaBelmonte, E.M. Barea, E. Palomares. Inorgan. Chimica Acta 361, 684 (2008).

[36] I. Abayev, A. Zaban, V.G. Kytin, A.A. Danilin, G. GarciaBelmonte, J. Bisquert. J. Solid State Electrochem. 11, 647 (2007).

[37] M.K. Nowotny, L.R. Sheppard, T. Bak, J. Nowotny. J. Phys. Chem. C 112, 5275 (2008).

[38] T. Bak, J. Nowotny, M.K. Nowotny. J. Phys. Chem. B 110, 21560 (2006).

[39] S.H. Kang, J.Y. Kim, Y.E. Sung. Electrochimica Acta 52, 5242 (2007).

[40] K. Zhu, N. Kopidakis, N.R. Neale, J. van de Lagemaat, A.J. Frank. J. Phys. Chem. B 110, 25174 (2006).

[41] S. Lakkis, C. Schlenker, B.K. Chakraverty, R. Buder, M. Marezio. Phys. Rev. B 14, 1429 (1976).

[42] M. Reece, R. Morrell. Proc. R. Soc. London A 384, 135 (1982).

[43] L.A. Bursill, M.G. Blanchin, D.J. Smith. Proc. R. Soc. London A 391, 351 (1984).

[44] M.G. Blanchin, L.A. Bursill, D.J. Smith. Proc. R. Soc. London A 391, 373 (1984).
[45] L.A. Bursill, M.G. Blanchin, D.J. Smith. Acta Cryst. B 40, 237 (1984).

[46] M.G. Blanchin, L.A. Bursill, D.J. Smith. Proc. R. Soc. London. Ser. A, Mathem. Phys. Sci. 391, 351 (1984).

[47] S.G. Park, B. Magyari-Köpe, Y. Nishi. IEEE Electron Dev. Lett. 32, 197 (2011).

[48] D.H. Kwon, K.M. Kim, J.H. Jang, J.M. Jeon, M.H. Lee, G.H. Kim, X.S. Li, G.S. Park, B. Lee, S. Han, M. Kim, C.S. Hwang. Nature Nanotechnology 5, 148 (2010).

[49] X. Zhong, I. Rungger, P. Zapol, O. Heinonen. Phys. Rev. B 91, 115143 (2015).

[50] X. Wei, R. Zhou, B. Balamurugan, R. Skomski, X.C. Zeng, D.J. Sellmyer. Nanoscale 4, 7704 (2012).

[51] A.P. Malozemoff. J. Appl. Phys. 63, 3874 (1988).

[52] B. Martínez, X. Obradors, L1. Balcells, A. Rouanet, C. Monty. Phys. Rev. Lett. 80, 5 (1998).

[53] W.H. Meiklejohn, C.P. Bean. Phys. Rev. 105, 904 (1957).

[54] K. Zhang, D.R. Fredkin. J. Appl. Phys. 79, 5762 (1996).

[55] L. Neel. Compt. Rend. 237, 1468 (1953).

[56] U. Gradmann. J. Magn. Magn. Mater. 54-57, 733 (1986). 